\title{
IgE-Mediated Hypersensitivity Reactions to Cannabis in Laboratory Personnel
}

\author{
T. Herzinger P.Schöpf B. Przybilla F. Ruëff \\ Klinik und Poliklinik für Dermatologie und Allergologie, Ludwig-Maximilians-Universität, München, Deutschland
}

\section{Key Words}

Cannabis $\cdot$ Hashish $\cdot$ Marijuana $\cdot$ Hypersensitivity •

Dermatitis, occupational $\cdot$ Rhinitis $\cdot$ Conjunctivitis

\begin{abstract}
Background: There have been sporadic reports of hypersensitivity reactions to plants of the Cannabinaceae family (hemp and hops), but it has remained unclear whether these reactions are immunologic or nonimmunologic in nature. Objective: We examined the IgE-binding and histaminereleasing properties of hashish and marijuana extracts by CAP-FEIA and a basophil histamine release test. Methods: Two workers at a forensic laboratory suffered from nasal congestion, rhinitis, sneezing and asthmatic symptoms upon occupational contact with hashish or marijuana, which they had handled frequently for 25 and 16 years, respectively. Neither patient had a history of atopic disease. Serum was analyzed for specific IgE antibodies to hashish or marijuana extract by research prototype ImmunoCAP, and histamine release from basophils upon exposure to hashish or marijuana extracts was assessed. Results were matched to those of 4 nonatopic and 10 atopic control subjects with no known history of recreational or occupational exposure to marijuana or hashish. Results: Patient 1 had specific IgE to both hashish and marijuana (CAP class 2), and patient 2 to marijuana only (CAP class 2). Controls proved negative for specific lgE except
\end{abstract}

for 2 atopic individuals with CAP class 1 to marijuana and 1 other atopic individual with CAP class 1 to hashish. Stimulation of basophils with hashish or marijuana extracts elicited histamine release from basophils of both patients and 4 atopic control subjects. Conclusions: Our results suggest an IgE-related pathomechanism for hypersensitivity reactions to marijuana or hashish.

Copyright $\odot 2011$ S. Karger AG, Basel

\section{Introduction}

Different subspecies of hemp (Cannabis) have been cultivated for the production of fibers (C. sativa sativa) or hallucinogenic drugs such as hashish or marijuana. While hashish is derived from the compressed stalked resin glands of the Cannabis plant, called trichomes, the term marijuana refers to the whole dried leaves and flowers [1]. When female plants are grown isolated from male plants to avoid pollination (so-called sinsemilla), they produce particularly large amounts of the hallucinogen tetrahydrocannabinol. Despite the immense popularity of cannabis-derived psychoactive drugs around the

The authors declare that they have no financial interest in the publication of this paper.

\section{KARGER}

Fax +41613061234 E-Mail karger@karger.ch www.karger.com
(C) 2011 S. Karger AG, Basel

$1018-2438 / 11 / 1564-0423 \$ 38.00 / 0$

Accessible online at:

www.karger.com/iaa
Correspondence to: PD Dr. med. Thomas Herzinger

Klinik und Poliklinik für Dermatologie und Allergologie

Ludwig-Maximilians-Universität

Frauenlobstrasse 9-11, DE-80337 Munich (Germany)

Tel. +49 895160 6054, E-Mail Thomas.Herzinger@med.uni-muenchen.de 
world, there have been only sporadic reports of hypersensitivity reactions to plants of the Cannabinaceae family [2-11]. Here, we report 2 further patients with cannabis allergy due to occupational allergen exposure.

\section{Patients and Methods}

\section{Patients}

A 52-year-old female technician (patient 1) working at a forensic laboratory had a 25-year history of occupational contact with cannabis products, but no recreational exposure. For 4 years she had been suffering from nasal congestion, sneezing and dyshidrotic hand eczema when handling hashish or marijuana, particularly the sinsemilla variant. A 49-year-old male physician (patient 2) working at the same institution had been handling cannabis products for 16 years. Recreational exposure was denied. For 8 years he had complained of nasal congestion, sneezing and occasionally mild asthma while working in the room where court exhibits were kept. Neither patient had a history of atopic disease.

\section{Standard Tests}

Specific IgE antibodies to various common aeroallergens (grass, mugwort and birch pollen) and total IgE were measured by UniCAP (Phadia, Freiburg, Germany).

\section{Cannabis-Specific IgE}

For measurement of specific IgE antibodies to hashish or marijuana, hashish and marijuana were extracted in saline, and an amount equaling $1 \mathrm{mg}$ of protein was biotinylated (Biotin Labeling Kit, Roche Diagnostics) and coupled to streptavidin-CAPs (Phadia) according to the manufacturer's instructions.

\section{Histamine Release Assay}

For histamine release testing, hashish and marijuana were extracted in saline. After centrifugation, the supernatant was adjusted to $1 \mathrm{mg}$ of protein $/ \mathrm{ml}$ and added to peripheral blood mononuclear cells prestimulated with IL-3 as described elsewhere [12]. Histamine release from basophils upon exposure to the extracts was analyzed using an Autoanalyzer II (Bran und Lübbe). Basophil histamine content was measured spectrofluorometrically after cell fragmentation, and absolute histamine release into the supernatant was determined with and without IL-3 stimulation.

\section{Controls}

Results were matched to those of 4 nonatopic and 8 atopic control subjects. Individuals were classified as atopic when skin prick test reactions to common aeroallergens (cat dander, house dust mite and/or grass pollen) were positive or when the patient reported a history of hay fever, asthma or atopic eczema. Individuals were considered nonatopic when they had neither a history of hay fever, asthma or atopic eczema, nor skin prick test reactions to the aeroallergens mentioned. Controls denied recreational or occupational exposure to marijuana or hashish.

Skin prick tests for marijuana or hashish were not performed because of legal constraints. The license to handle cannabis products was granted exclusively for testing in vitro. No use on human subjects was allowed.

\section{Results}

Specific IgE antibodies were demonstrable in the serum of patient 1 to both hashish $(2.82 \mathrm{kU} / \mathrm{l}$; CAP class 2$)$ and marijuana (0.72 kU/1; CAP class 2), and in the serum of patient 2 to marijuana only (0.86 kU/l; CAP class 2$)$. Controls proved negative for marijuana- or hashish-specific IgE except for 2 atopic individuals to marijuana $(0.38$ and $0.68 \mathrm{kU} / 1$, respectively; CAP class 1$)$ and 1 atopic individual to hashish ( $0.5 \mathrm{kU} / 1$; CAP class 1 ; fig. 1a).

Histamine release was triggered by hashish and marijuana extracts in both patients and 4 control subjects (fig. 1b). There was no association between specific IgE levels and atopic disease.

\section{Discussion}

Immediate-type allergy to marijuana or hashish has rarely been documented. Three previously reported cases from Europe were also related to handling of hashish or marijuana in forensic laboratories $[6,7,11]$. Two more cases were connected to the recreational consumption of marijuana $[3,13]$. A further report described a Californian patient who developed a severe anaphylactic reaction following the intravenous administration of a marijuana concoction [9]. Urticaria, facial angioedema and dyspnea after the ingestion of hemp-seed-crusted food in a restaurant have also been observed [2]. The scarcity of documented allergic reactions related to recreational Cannabis consumption may simply reflect underreporting of complaints by patients due to the illegal nature of the use of the drug in most countries. It is said that marijuana smokers frequently get red eyes while smoking. Still, it has remained unclear whether these reactions are immunologic or nonimmunologic in nature.

However, cannabis products seem to act as allergens which are also recognized by $\operatorname{IgE}$ antibodies of atopic controls who had not knowingly been exposed to cannabis. We do not know the reason for this probable crossreactivity. Cannabis pollen is still not common in southern Germany. Corresponding sensitization is predominantly found in regions where cultivation of Cannabis plants is common, such as in south- and midwestern USA and central India $[4,14,15]$. However, it is unclear to which degree sensitization to cannabis pollen corresponds to clinical symptoms upon exposure to hashish or marijuana. Rather than from contact to hemp pollen, sensitization may also have developed through contact with nonhallucinogenic hemp products. Such hemp 
Fig. 1. a Levels of specific IgE to hashish or marijuana extracts in patients $(\mathrm{P})$ and 8 atopic (AC) and 4 nonatopic (NAC) controls. b Histamine release from basophils from the same patients and controls as in a was analyzed following incubation with hashish or marijuana extracts.
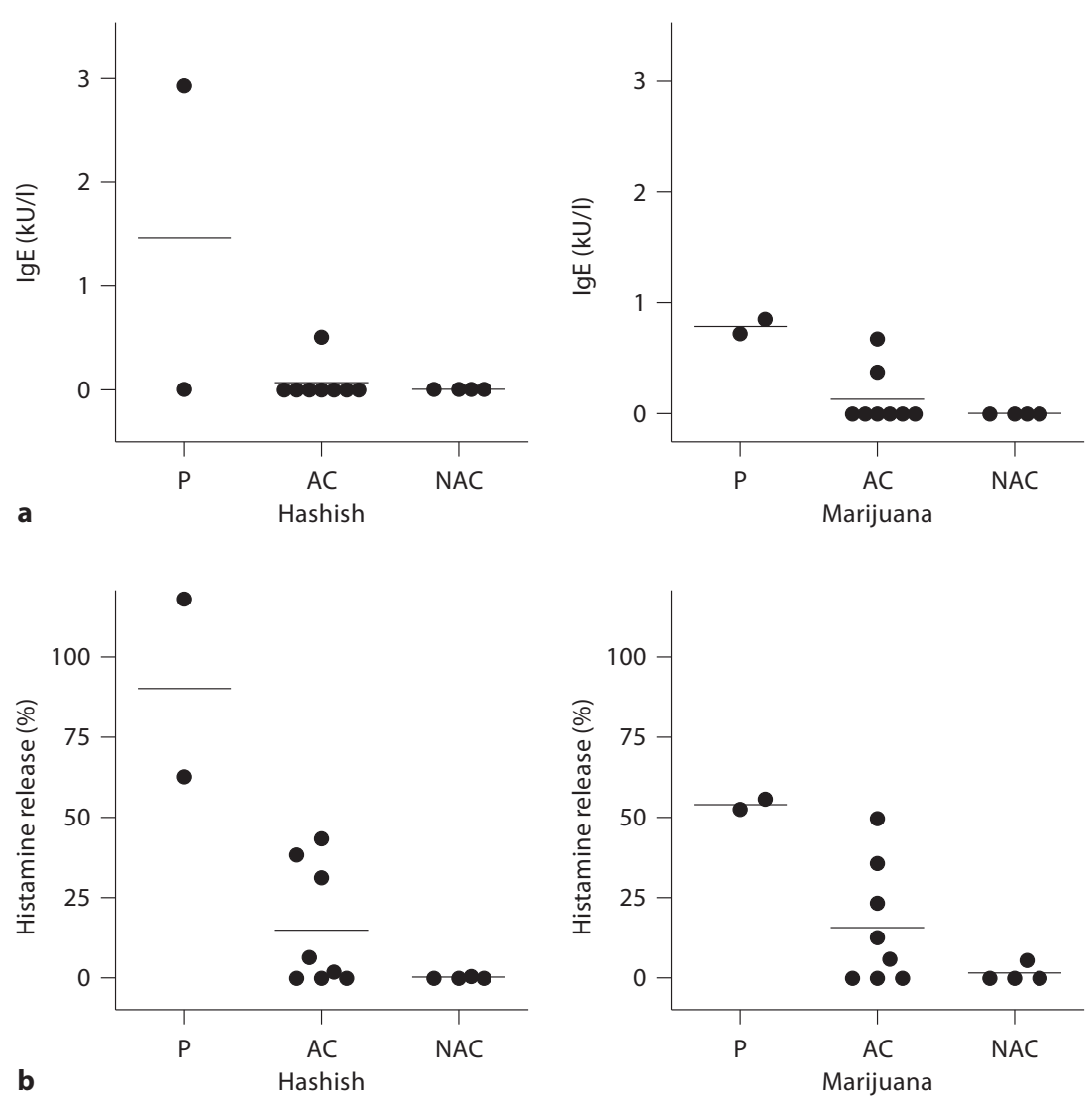

products are fairly common in textiles/fibers or foods (cereals, bird seed). Another possible reason for elevated $\mathrm{IgE}$ may be cross-reactivity with cross-reacting carbohydrate determinants.

Another putative reason for the reactivity of the sera could have been contamination of the cannabis specimens used for the CAP or histamine release assays by mold allergens. However, the sera of neither patient contained specific IgE to Aspergillus fumigatus, Cladosporium herbarum or Alternaria alternata, making mold contaminants an unlikely source of the reactivity of the sera.

Sensitization to marijuana and/or hashish was reflected by demonstrable levels of specific IgE antibodies and allergen-induced release of histamine from basophils in our patients, showing that hypersensitivity to hashish and marijuana is immunologic in nature. We did not identify the immunogenic component of Cannabis triggering the response in our patients. However, it seems unlikely that Cannabis pollen contained the allergen in patient 1 since she reported the most severe reactions upon contact to sinsemilla, i.e. female Cannabis plants that are not allowed to be pollinated in order to maximize production of the hallucinogen tetrahydrocannabinol.

\section{Acknowledgments}

We thank the Federal Opium Agency (Bundesopiumstelle) of the Federal Institute for Drugs and Medical Devices (Bundesinstitut für Arzneimittel und Medizinprodukte) for the permission to acquire blossoms and leaves of Cannabis sativa for in vitro testing. We also thank the Bavarian State Office of Criminal Investigation for providing blossoms and leaves of Cannabis sativa. 


\section{References}

1 Brown DT (ed): Cannabis. The Genus Cannabis, vol. 4. Amsterdam, Harwood Academic Publishers, 1998, p 272.

2 Stadtmauer G, Beyer K, Bardina L, Sicherer $\mathrm{SH}$ : Anaphylaxis to ingestion of hempseed (Cannabis sativa). J Allergy Clin Immunol 2003;112:216-217.

3 Stockli SS, Bircher AJ: Generalized pruritus in a patient sensitized to tobacco and cannabis. J Dtsch Dermatol Ges 2007;5:303-304.

4 Stokes JR, Hartel R, Ford LB, Casale TB: Cannabis (hemp) positive skin tests and respiratory symptoms. Ann Allergy Asthma Immunol 2000;85:238-240.
5 de Larramendi CH, Carnes J, Garcia-Abujeta JL, Garcia-Endrino A, Munoz-Palomino E, Huertas AJ, Fernandez-Caldas E, Ferrer A: Sensitization and allergy to Cannabis sativa leaves in a population of tomato ( $L y c o-$ persicon esculentum)-sensitized patients. Int Arch Allergy Immunol 2008;146:195-202.

6 Lindemayr H, Jager S: Beruflich erworbene Typ I-Allergie durch Hanfpollen und Haschisch. Derm Beruf Umwelt 1980;28:1719.

7 Majmudar V, Azam NA, Finch T: Contact urticaria to Cannabis sativa. Contact Dermatitis 2006;54:127.

8 Mayoral M, Calderon H, Cano R, Lombardero M: Allergic rhinoconjunctivitis caused by Cannabis sativa pollen. J Investig Allergol Clin Immunol 2008;18:73-74.

9 Perez JA Jr: Allergic reaction associated with intravenous marijuana use. J Emerg Med 2000;18:260-261.
10 Vidal C, Fuente R, Iglesias A, Saez A: Bronchial asthma due to Cannabis sativa seed. Allergy 1991;46:647-649.

11 Williams C, Thompstone J, Wilkinson M: Work-related contact urticaria to Cannabis sativa. Contact Dermatitis 2008;58:62-63.

12 Eberlein-Konig B, Michel G, Ruzicka T, Przybilla B: Modulation of histamine release in vitro by $\mathrm{fk} 506$ and interleukin-3 is determined by sequence of incubation. Arch Dermatol Res 1997;289:606-608.

13 Anibarro B, Fontela JL: Allergy to marihuana. Allergy 1996;51:200-201.

14 Singh AB, Kumar P: Aeroallergens in clinical practice of allergy in India. An overview. Ann Agric Environ Med 2003;10:131-136.

15 Freeman GL: Allergic skin test reactivity to marijuana in the Southwest. West J Med 1983;138:829-831. 